\title{
Panda's dream
}

\section{André Simon}

\section{Legend}

Legend has it that the fur of Pandas was originally all pure white. The white Pandas were so different from all the other animals in the forest. They had a special way of living, nourishing themselves with fresh bamboo leaves. They were therefore obliged to live only in bamboo forests. Mother pandas have only one cub. The other animals have multiple cubs, so they quickly outnumber the small panda families. In spite of these differences the smaller panda families live in close knit groups. It is well known however that all children throughout the world like to play with them.

Legend has it that a schoolgirl was once playing joyfully with a white panda cub when a leopard happened by and noticed them and attacked them both. The panda escaped by running away, but the leopard killed the schoolgirl. In the core of any happiness there's a seed of sadness and the joyful playing ended in tragedy.

The day after the funeral of the noble schoolgirl, who had saved the panda cub, all panda families participated in a ceremony. In a gesture of mourning they all plunged their paws in black ash. After the ceremony the pandas embraced one another and wiped their tears away with their paws, which were covered

Dr.med. André Sim Dörflistrasse 14

CH-8057 Zürich

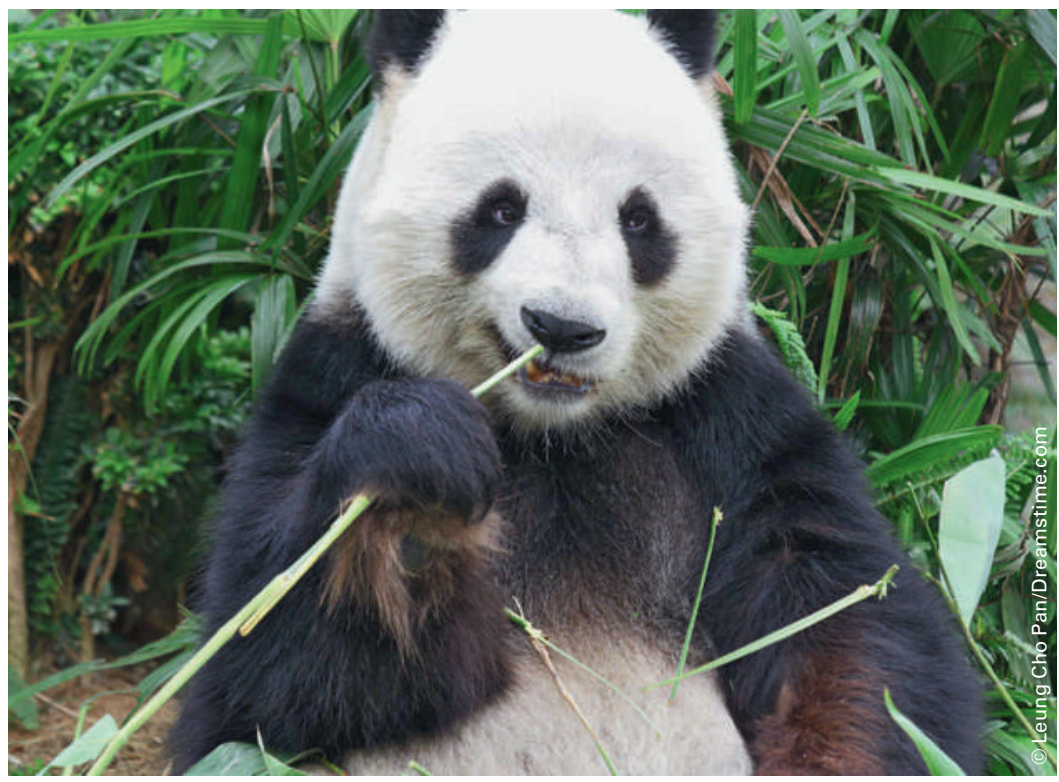

with black ash. This action covered their white fur coat with black patches and gave them the distinctive black eyes.

\section{Dream}

I am slowly walking along a forest trail that runs next to a clear water creek that I can see my reflection in. All around me the trees cast shadows, the flowers fill the air with their scent and the birds are singing. I stop to enjoy eating the delicate wild strawberries and to watch the squirrels and other unknown forest friends scurrying about. As I keep walking I come across a wooden cabin. I go inside and fall asleep.

Suddenly, a bright light appears in my new woodland home and interrupts my sleep. In front of me there is an apparition, a beautiful shining being dressed in brilliant white. "Why have you woken me?» I ask. It replies: «Dear panda-boy, your ancestors once lived happily in their own dream-forests. Observe the trees and plants that are growing here nowadays and immediately you will feel sadness for them. The branches of the trees are already dried out and dead because of air pollution. Trees without their branches, leaves and blooming flowers are no longer homes for the singing birds as well as for vivid butterflies. I offer divine help to all sentient beings, so I interrupt your sleep to return you to your dream-forest. Joyful dreams mean pleasure during sleep and I am able to overwhelm you with this pleasure. Once, I made Chuang Tzu dream that he was a vivid butterfly which flutters from flower to flower. His dreams were so real that when he awoke he was confused; was he a man still dreaming he was a butterfly or was it a butterfly dreaming it was a man?»

Your return to today's world from your dream would be very painful. Now you can remain in your dream-forest forever. If I had not intervened, you would be back again in today's world. After that, no one would spell my real name: a n gel.

A dream dreamed by a dreamer is a peaceful land where the only weapon is kindness,

where all the children smile

and the panda-families play joyfully. 